\title{
Cilostazol inhibits hyperglucose-induced vascular smooth muscle cell dysfunction by modulating the RAGE/ERK/NF-KB signaling pathways
}

Sheng-Chiang Su ${ }^{1,4}$, Yi-Jen Hung ${ }^{1,4,6^{*}}$, Chia-Luen Huang ${ }^{1,4}$, Yi-Shing Shieh ${ }^{2,3,6}$, Chu-Yen Chien ${ }^{4}$, Chi-Fu Chiang ${ }^{2,4}$, Jhih-Syuan Liu', Chieh-Hua Lu', Chang-Hsun Hsieh', Chien-Ming Lin ${ }^{5}$ and Chien-Hsing Lee ${ }^{1,4,6^{*}}$ (D)

\begin{abstract}
Background: Increasing evidence suggests that high glucose (HG) causes abnormalities in endothelial and vascular smooth muscle cell function (VSMC) and contributes to atherosclerosis. Receptor for advanced glycation endproducts (RAGE) has been linked to the pathogenesis of both the macrovascular and microvascular complications of diabetes. Cilostazol is used to treat diabetic vasculopathy by ameliorating HG-induced vascular dysfunction.

Objectives: In this study, we investigated whether the cilostazol suppression of HG-induced VSMC dysfunction is through RAGE signaling and its possible regulation mechanism.

Method: We investigated the effect of HG and cilostazol on RAGE signaling in A7r5 rat VSMCs. Aortic tissues of streptozotocin (STZ) diabetic mice were also collected.

Results: Aortic tissue samples from the diabetic mice exhibited a significantly decreased RAGE expression after cilostazol treatment. HG increased RAGE, focal adhesion kinase (FAK), matrix metalloproteinase-2 (MMP-2), intercellular cell adhesion molecule-1 (ICAM-1) and vascular cell adhesion molecule-1 (VCAM-1) expressions, and was accompanied with increased reactive oxygen species (ROS), cell proliferation, adhesion and migration. Cilostazol significantly reversed HG-induced RAGE, ROS, downstream gene expressions and cell functions. RAGE knockdown significantly reversed the expressions of HG-induced vasculopathy related gene expressions and cell functions. Cilostazol with RAGE knockdown had additive effects on downstream ERK/NF-KB signaling pathways, gene expressions and cell functions of A7r5 rat VSMCs in HG culture.

Conclusions: Both in vitro and in vivo experimental diabetes models showed novel signal transduction of cilostazol-mediated protection against HG-related VSMC dysfunction, and highlighted the involvement of RAGE signaling and downstream pathways.
\end{abstract}

Keywords: Cilostazol, Vascular smooth muscle, RAGE, Diabetes

\footnotetext{
* Correspondence: metahung@yahoo.com; doc10383@gmail.com

${ }^{1}$ Division of Endocrinology and Metabolism, Department of Internal

Medicine, Tri-Service General Hospital, National Defense Medical Center,

Taipei, Taiwan

Full list of author information is available at the end of the article
}

(c) The Author(s). 2019 Open Access This article is distributed under the terms of the Creative Commons Attribution 4.0 International License (http://creativecommons.org/licenses/by/4.0/), which permits unrestricted use, distribution, and reproduction in any medium, provided you give appropriate credit to the original author(s) and the source, provide a link to the Creative Commons license, and indicate if changes were made. The Creative Commons Public Domain Dedication waiver (http://creativecommons.org/publicdomain/zero/1.0/) applies to the data made available in this article, unless otherwise stated. 


\section{Introduction}

Type 2 diabetes is the most prevalent and serious metabolic disease worldwide [1]. Epidemiological studies have identified diabetes to be an independent risk factor for atherosclerosis-associated morbidity and mortality [2]. In addition, recent studies have demonstrated that chronic hyperglycemia and reactive oxygen species (ROS) are involved in the development of atherosclerosis through various pathways. Moreover, ROS have been shown to be involved in the progression of endothelial cell dysfunction, proliferation and migration of vascular smooth muscle cells (VSMCs), and expressions of adhesion molecules such as intercellular adhesion molecule-1 (ICAM-1) and vascular cell adhesion molecule-1 (VCAM-1) [3].

The receptor for advanced glycation end-products (RAGE) was initially identified as the signal transducingreceptor of advanced glycation end-products (AGEs) [4]. Driven by sustained hyperglycemia and oxidative stress, enhanced AGE generation coupled with RAGE hyperactivity has been demonstrated to be a critical pathway involved in diabetic micro and macrovascular complications [5]. RAGE is physiologically expressed in a number of cells involved in immune/ inflammatory responses, including monocytes/macrophages, granulocytes, endothelial cells, VSMCs, and adipocytes $[5,6]$. RAGE is a multi-ligand receptor of the immunoglobulin superfamily involved in diverse ligands related to the pathogenesis of atherosclerosis. The exposure of vascular endothelial cells to various RAGE ligands, including AGEs, S100/calgranulins, and high-mobility group box 1 protein (HMGB-1), has been shown to augment RAGE activation resulting in enhanced generation of ROS and activation of the transcription factor NF- $\mathrm{kB}$ [7]. In turn, this has been confirmed to lead to sustained upregulation of proinflammatory mediators, adhesion molecules and to the initiation of atherosclerosis [8].

Cilostazol, a phosphodiesterase type 3 (PDE3) inhibitor, has been regarded as possessing antiplatelet and vasodilatory effects, and inducing increased concentrations of intracellular $3^{\prime}-5^{\prime}$ cyclic adenosine monophosphate (cAMP) levels [9]. Cilostazol acts as a vasodilator, antithrombotic antiplatelet agent, and has been demonstrated to be involved in various stages of the atherosclerotic process [10]. The anti-atherogenic effect of cilostazol has been ascribed to its ability to suppress superoxide, resulting in attenuation of NF- $\mathrm{kB}$ activation, VCAM-1/monocyte chemotactic protein-1 (MCP-1) expressions and monocyte recruitment in low-density lipoprotein (LDL) receptor-null mice [11]. In addition, cilostazol has been shown to inhibit VSMC proliferation, thereby improving peripheral blood flow and insulin sensitivity via attenuation of inflammation processes [12]. Recent clinical studies have revealed that cilostazol can have effects of reduced triglyceride levels and increased high-density lipoprotein (HDL) on patients with peripheral arterial occlusive disease (PAOD), thereby improving postprandial lipemia in patients with diabetes [13].

In our previous report, we discovered that cilostazol therapy effectively ameliorated the severity of PAOD, which was defined as an improvement in ankle-brachial index $(\mathrm{ABI})$ in patients with type 2 diabetes. Furthermore, augmentation of the plasma circulating soluble form of RAGE (sRAGE) and attenuation of proinflammatory markers as well as adhesion molecules after cilostazol treatment were also observed. There was also a significant association between the improvement in ABI and the augmentation of plasma sRAGE, and hence enhancement of plasma sRAGE level was regarded as an independent factor of improving the severity of peripheral arterial insufficiency in type 2 diabetic patients [13]. However, it is still unclear whether cilostazol can improve diabetes-associated atherosclerosis through RAGE pathways to influence downstream signaling such as inflammation and adhesion molecules. Therefore, the aim of this study was to investigate the molecular mechanism of cilostazol on the development of diabetic vasculopathy, and whether that was relevant to RAGE and its downstream signaling.

\section{Materials and methods Animal experiments}

Male BALB/c mice were obtained from the National Laboratory Animal Breeding and Research Center (Taipei, Taiwan). To induce type 2 diabetes mellitus, the mice were housed in laboratory cages and fed with a high-fat (HF) diet (40\% fat, Research Diets, Inc., NJ, USA) [14] for 3 weeks. Subsequently, the mice received $75 \mathrm{mg} / \mathrm{kg}$ and $150 \mathrm{mg} / \mathrm{kg}$ of intravenous STZ, 5 days apart. Feed was not withheld from any of the animals at the time of STZ administration. After induction, blood glucose was measured daily by tailvein sampling using a ACCUCHEK glucometer (Roche, Basel, Switzerland). Animals with a blood glucose level more than $11.1 \mathrm{mmol} / \mathrm{L}(200 \mathrm{mg} / \mathrm{dL})$ were included in this study. Six mice were treated with cilostazol for 2 months, where cilostazol was diluted from $0.5 \%$ CMC (carboxymethyl cellulose sodium salt), which was used as a vehicle control. Another six mice were treated with $0.5 \%$ CMC for 2 months. Finally, the animals were sacrificed and blood and ascending aorta samples were taken. The Animal Ethics Board of National Defense Medical Center (Taipei, Taiwan) approved all animal experimental procedures.

\section{Immunohistochemistry assay}

Animal tissue samples in paraffin blocks were cut into 4$\mu \mathrm{m}$ sections, which were dewaxed and subjected to microwave antigen retrieval. Endogenous peroxidase activity and nonspecific binding were blocked by incubation with 
$3 \%$ hydrogen peroxide and non-immune serum, respectively. Slides were then incubated with anti-RAGE antibody (Millipore, \#051050, MA, USA) at 1:250 at $4{ }^{\circ} \mathrm{C}$ overnight, and anti-rabbit secondary antibody for $1 \mathrm{~h}$. Diaminobenzidine hydrochloride (Dako, Carpinteria, CA, USA) was then added to localize positive staining sequentially by light microscopy. The sections were counterstained with hematoxylin and cover slipped.

\section{Protein isolation from frozen/OCT-embedded samples}

The tissue sections were moved to a 2-ml tube containing ceramic beads ( $2.8 \mathrm{~mm}$, Bertin Technologies, France). Lysis buffer (50 mM Tris- $\mathrm{HCl}$ [pH 7.4], $150 \mathrm{mM} \mathrm{NaCl}, 2 \mathrm{mM}$ EDTA, 1\% NP-40, 0.1\% SDS, protease inhibitor) was added, and the samples were homogenized by vortex and grinding in a homogenizer (Precellys 24 , Bertin Technologies). The samples were kept on ice for $30 \mathrm{~min}$ to complete the lysis reaction followed by centrifugation $\left(4{ }^{\circ} \mathrm{C}, 13000 \mathrm{~g}, 15 \mathrm{~min}\right)$ to collect the supernatant. The samples were then collected and stored at $-80^{\circ} \mathrm{C}$.

\section{Cell culture and reagents}

Smooth muscle cell lines from rat thoracic aorta, A7r5 (RRID:CVCL_0137), were purchased from the Bioresource Collection and Research Center (BCRC, Taiwan). Cells were cultured in Dulbecco's Modified Eagle's Medium (DMEM) and supplemented with $10 \%$ fetal bovine serum (FBS), and incubated at $37{ }^{\circ} \mathrm{C}$ in $5 \% \mathrm{CO} 2$. The cells were seeded at a density of $1.5 \times 10^{6}$ cells on a $10 \mathrm{~cm} 2$ dish in DMEM with $10 \%$ FBS for $24 \mathrm{~h}$. After serum starvation for $24 \mathrm{~h}$ in DMEM with $0.5 \% \mathrm{FBS}$, the cells were stimulated by high glucose (HG). A7r5 cells were grown in $30 \mathrm{mmol} / \mathrm{L}$ glucose, and controls received $25 \mathrm{mmol} / \mathrm{L}$ mannitol and $5 \mathrm{mmol} / \mathrm{L}$ glucose. Cilostazol (kindly provided by Otsuka Pharmaceutical Co. Ltd., Tokushima, Japan) was dissolved in dimethyl sulfoxide. The final concentration of dimethyl sulfoxide in the culture medium was less than $0.1 \%$, which had no effect on VSMCs. The cells were incubated for $24 \mathrm{~h}$ with 100 and $200 \mu \mathrm{M}$ cilostazol after high glucose stimulation. All of the chemical compounds, N-acetylcysteine (NAC), U0126 and PDTA were purchased from Cell Signaling (Danvers, CO, USA).

\section{siRNA transfection}

Knockdown of RAGE was performed using specific single or pooled siRNAs purchased from Dharmacon RNAi Technologies (Thermo, MA, USA). SiGENOME non-target siRNAs served as negative controls, and transfection was carried out according to the manufacturer's protocol.

\section{Intracellular ROS}

A7r5 cells were plated in a 6-well plate, grown to confluence, and harvested by trypsinization. Cell pellets were washed with PBS and centrifuged for $5 \mathrm{~min}$ at $1000 \times \mathrm{g}$ at room temperature. The cell pellets were resuspended in $10 \mu \mathrm{mol} / \mathrm{L}$ of CM-H2DCFDA by gently pipetting up and down. The cells were then incubated in a cell incubator in the dark for $45 \mathrm{~min}$, followed immediately by flow cytometry analysis (BD Bioscience).

\section{Cell proliferation assay}

A7r5 cells were cultured at a density of $1.5 \times 10^{5}$ cells/ well in a 24-well plate. The cells were exposed to various stimuli. A methylene blue dye assay was used to evaluate the effect of high glucose and cilostazol on cell growth. The resulting cell growth was measured at $540 \mathrm{~nm}$ and calculated graphically in comparison with the growth of the controls.

\section{Cell adhesion assay}

A7r5 cells $\left(1 \times 10^{6}\right.$ cells $\left./ \mathrm{ml}\right)$ were cultured in normoglycemic $(5 \mathrm{mmol} / \mathrm{L}$ glucose) and hyperglycemic $(30 \mathrm{mmol} /$ $\mathrm{L}$ glucose) conditions in a 6-well culture plate. The cells were Incubated for $24 \mathrm{~h}$ in a CO2 incubator. THP- 1 was fluorescence-labeled with calcein-AM by incubating the cells $\left(1 \times 10^{7}\right.$ cells $\left./ \mathrm{ml}\right)$ with $5 \mu$ calcein-AM in RPMI 1640 for $30 \mathrm{~min}$ at $37^{\circ} \mathrm{C}$ in a $\mathrm{CO} 2$ incubator. The cells were washed three times with PBS to remove excess dye and resuspended in phenol red-free RPMI 1640 (with $10 \%$ FBS) at a density of $1 \times 10^{6}$ cells $/ \mathrm{ml}$. After high glucose and cilostazol treatment, the A7r5 cells were cocultured with calcein-AM-labeled cells $\left(1 \times 10^{6}\right.$ cells $/ \mathrm{ml}$ in 6- well) in a $\mathrm{CO} 2$ incubator at $37^{\circ} \mathrm{C}$ for $1 \mathrm{~h}$. The $\mathrm{A} 7 \mathrm{r} 5$ cells were then washed four times with PBS to remove the non-adherent calcein-AM-labeled cells and replaced with $1.0 \mathrm{ml}$ of PBS. The fluorescence of each well was measured using a fluorescence microscopy with excitation and emission wavelengths of $480 \mathrm{~nm}$ and $530 \mathrm{~nm}$, respectively.

\section{Migration assay}

The migration ability of A7r5 cells was examined using 24well culture insert-based assays (BD Biosciences, Franklin Lakes, NJ, USA). The culture insertion, with a pore size of $8 \mu \mathrm{m}$, was pre-coated to a density of $100 \mu \mathrm{g} /$ insert of gelatin (Sigma, MO, USA). Cells were suspended in medium containing 10\% NuSerum (Corning, New York, U.S), and $2.5 \times 10^{4}$ cells were added to the insert. After incubating for $10 \mathrm{~h}$ at $37^{\circ} \mathrm{C}$, the cells that migrated through a Fluoro-Blok membrane (Corning, New York, U.S) were stained with propidium iodine, and fluorescence images were taken. The cells were then counted with Image J software.

\section{Western blot analysis}

Whole cell lysates for Western blotting were harvested in RIPA buffer (1\% SDS and $10 \mathrm{mM}$ Tris buffer, $\mathrm{pH} 7.4)$ containing protease and phosphatase inhibitors (Thermo, 
Wilmington, DE, USA). Protein concentrations in the supernatants were determined using a Pierce BCA Protein Assay Kit (Thermo, Rockford, IL, USA). Thirty micrograms of protein were separated on 5-15\% gradient SDSPAGE gel and transferred to polyvinylidene difluoride membranes (Millipore, Bedford, MA, USA) by wet blotting using an electroblotter (Hoefer system). Membranes were blocked for $1 \mathrm{~h}$ at $25^{\circ} \mathrm{C}$ with $2 \%$ bovine serum albumin or $5 \%$ skimmed milk in Tris-buffered saline and Tween 20 (TBST). The membranes were incubated with appropriate dilutions of the primary antibodies: RAGE antibody (SC-74473 [1:1000 dilution]; Santa Cruz, Dallas, USA), I-CAM antibody (SC-8439 [1:1000 dilution]; Santa Cruz, Dallas, USA), V-CAM antibody (SC-13160 [1:1000 dilution]; Santa Cruz, Dallas, USA), FAK antibody (3285 [1:1000 dilution]; Cell Signaling, Danvers, MA, USA), p65 antibody (3033 [1:1000 dilution]; Cell Signaling, Danvers, MA, USA), ІкB $\alpha$ antibody (9242 [1:1000 dilution]; Cell Signaling, Danvers, MA, USA), GAPDH antibody (5174 [1:2000 dilution]; Cell Signaling, Danvers, MA, USA), Phospho-JNK antibody (9255 [1:1000 dilution]; Cell Signaling, Danvers, MA, USA), JNK antibody (9252 [1:1000 dilution]; Cell Signaling, Danvers, MA, USA), PhosphoERK antibody (9101 [1:1000 dilution]; Cell Signaling, Danvers, MA, USA), ERK antibody (9102 [1:1000 dilution]; Cell Signaling, Danvers, MA, USA), MMP2 antibody (13, 405 [1:1000 dilution]; Millipore, Danvers, MA, USA), $\beta$ actin antibody (600-501 [1:3000 dilution]; Novus, CO, USA), overnight at $4{ }^{\circ} \mathrm{C}$. After being washed in TBST three times, the membranes were incubated for $60 \mathrm{~min}$ with HRP-conjugated goat anti-rabbit or anti-mouse secondary antibodies at $25^{\circ} \mathrm{C}$. Signals were visualized using horseradish peroxidase-conjugated secondary antibodies and an enhanced chemiluminescence assay. Band intensities were determined using a UVP (ChemStudio series imagers) imaging system.

\section{Statistical analysis}

Values are expressed as means \pm SEM. Immunoblot data are expressed as means \pm SEM of band intensity relative to the controls. All experiments were repeated for three times. Groups were analyzed for differences by one-way ANOVA followed by Tukey's test. Significance was considered at $P<0.05$. All statistical analyses were performed using SPSS software (version 20.0; Chicago, II, USA).

\section{Results}

Effects of cilostazol on the artery expression of RAGE and possible associated signaling pathways in the mice with STZ-induced diabetes

In order to investigate the role of RAGE and possible associated signaling pathways in diabetic vasculopathy, the expression of RAGE and possible downstream signaling molecules were determined by western blot in the aortas of the STZ-induced diabetic mice. The protein expression of RAGE, focal adhesion kinase (FAK), matrix metalloproteinase-2 (MMP-2), intercellular cell adhesion molecule-1 (ICAM-1) and vascular cell adhesion molecule-1 (VCAM-1) were higher in the STZ diabetic mice compared to the control mice, and the expression of RAGE, FAK, MMP-2, ICAM-1 and VCAM-1 were significantly decreased after cilostazol treatment (Fig. 1a). Consistent with the above molecules expression levels, the STZ diabetic mice exhibited both an increased protein expression of RAGE and downstream signaling pathways (P-38, JNK, ERK phosphorylation and nuclear p65 expression and downregulated the expression of $\mathrm{I} \kappa \mathrm{B} \alpha)$ compared to the control group, and significantly decreased RAGE and downstream signaling proteins expression after cilostazol treatment (Fig. 1a). We further evaluated the distribution and expression of RAGE in the aortas by immunohistochemical staining, and found that RAGE was mainly detected in both the endothelium and VSMCs. In addition, the staining of RAGE protein was more prominent in the aortic sections of the STZ diabetic mice compared to the control mice. After cilostazol treatment, the staining of RAGE protein was decreased in the STZ diabetic mice (Fig. 1b, c and d).

\section{Effects of HG concentration and cilostazol on the protein expressions of RAGE, FAK, MMP-2, ICAM-1 and VCAM-1}

To determine whether HG and cilostazol affects the expression of RAGE in VSMCs, A7r5 cells were incubated for $24 \mathrm{~h}$ with 100 and $200 \mu \mathrm{M}$ cilostazol after stimulation with 5 and $30 \mathrm{mM}$ glucose. After $30 \mathrm{mM}$ glucose treatment, the protein expressions of RAGE, FAK, MMP-2, ICAM-1 and VCAM-1 were significantly increased (Fig. 2a and $\mathrm{b})$. We then investigated the effect of cilostazol on HG-induced VSMC dysfunction, and the results showed a significant suppression of RAGE, FAK, MMP-2, ICAM-1 and VCAM-1 expressions in a dose-dependent manner (Fig. 2a and b).

\section{Effects of cilostazol on HG-induced oxidative stress, proliferation, adhesion and migration in A7r 5 cells}

To further evaluate HG-induced oxidative stress and associated VSMC dysfunction, we examined ROS production and cell proliferation, adhesion and migration of VSMCs. After $30 \mathrm{mM}$ glucose treatment, the ROS production and cell proliferation, adhesion and migration of VSMCs were significantly increased (Fig. 3a-d). We then investigated the effect of cilostazol on HG-induced VSMC dysfunction, and the results showed a significant dose-dependent decrease in ROS production and reversal of cell proliferation, adhesion and migration after the addition of cilostazol (Fig. 3a-d). 


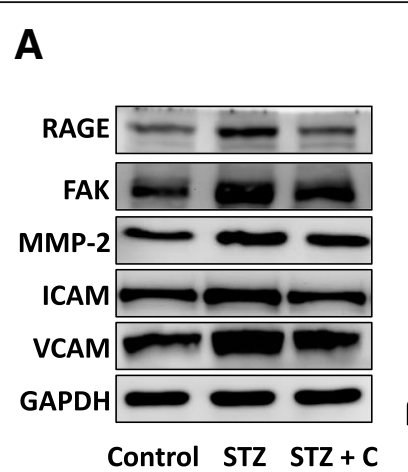

B

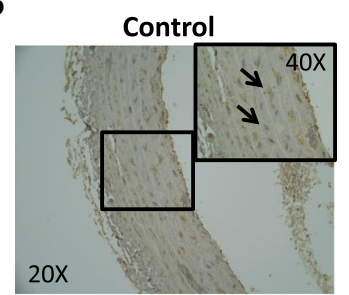

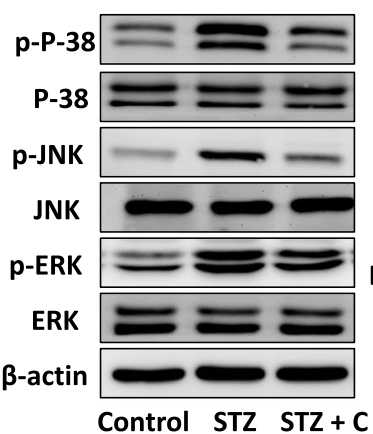

C

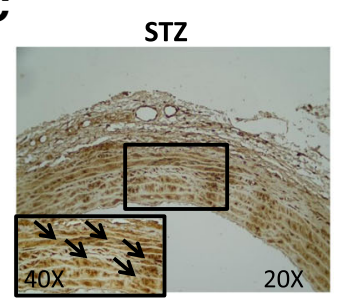

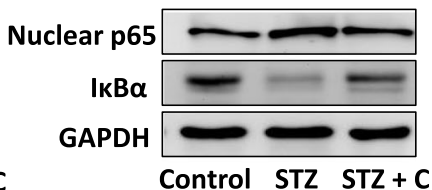

D

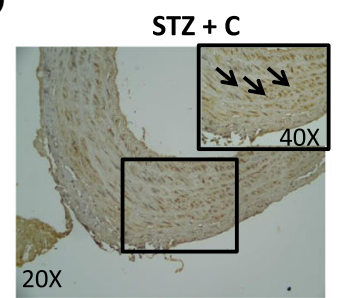

Fig. 1 RAGE and possible associated signaling pathways were elevated in STZ-induced diabetic mice and attenuated after cilostazol treatment. a, protein levels of RAGE and possible associated signaling molecules in vascular tissues in mice treated with STZ and/or cilostazol were measured by Western blot analysis. Immunohistochemical staining of RAGE was analyzed in the intima layer of vessels in mice from the control group (b), STZ-induced diabetes (c) and combined treatment with STZ and cilostazol (d). Western blots were independently repeated three to six times GAPDH and $\beta$-actin served as loading control

\section{Effects of cilostazol on HG-induced expression of RAGE} and associated signaling pathways in A7r5 cells

Previous studies have reported that RAGE has many diverse signaling capabilities through P-38, JNK, ERK, and NF-kB pathways by which it regulates cell function. In this study, we detected HG-induced A7r5 cell dysfunction including cell proliferation, adhesion and migration. To further elucidate the downstream signaling pathways of RAGE after HG treatment, we examined P-38, JNK, ERK, and NF- $к B$ signaling which are known to be highly associated with proliferation, adhesion and migration functions. Along with an increased expression of RAGE, HG significantly activated P-38, JNK, ERK phosphorylation and nuclear p65 expression and downregulated the expression of I $\mathrm{B} \alpha$ after treatment, and cilostazol significantly suppressed and reversed the effect of HG (Fig. 4a, b).

\section{Effect of cilostazol and RAGE knockdown on HG-induced RAGE signaling pathways and associated functional proteins in A7r5 cells}

In order to confirm the effects of HG treatment and cilostazol on A7r5 cells through RAGE signaling, we investigated whether RAGE knockdown in A7r5 cells had a similar effect to cilostazol on HG culture. The A7r5 cells were infected with RAGE siRNA and control siRNA vectors and cultured in $30 \mathrm{mM}$ glucose. We detected significant changes in the downstream signaling pathways (ERK phosphorylation and nuclear p65 expression and downregulated
I $\mathrm{B} \alpha \alpha$ expression) and associated functional proteins (FAK, MMP-2, ICAM-1 and VCAM-1 expressions) of the RAGEsiRNA-infected A7r5 cells in HG culture compared with the control-siRNA-infected A7r5 cells in HG culture (Fig. 5a, b). Furthermore, compared with cilostazol or RAGE knockdown alone, we found additive effects in the downstream signaling and associated proteins of the cilostazol and RAGE knockdown A7r5 cells (Fig. 5a, b). These results suggested that RAGE signaling was responsible for cilostazol and HG-induced VSMC dysfunction.

\section{ROS generation was involved in the HG and cilostazol effect in A7r5 cells}

ROS are induced under diabetic conditions, and may be involved in the progression of pancreatic $\beta$-cell dysfunction, insulin resistance and atherosclerosis found in patients with type 2 diabetes. Clinically, drugs which have anti-oxidant effects may have beneficial effects on the pathogenesis and complications of diabetes. We found that HG induced ROS production, and that this effect was decreased after cilostazol treatment (Fig. 3a). We further used an ROS inhibitor, NAC, to confirm that ROS were involved in HG-induced RAGE signaling pathways and associated functional proteins in the A7r5 cells. The data revealed significant changes in the downstream signaling pathways (ERK phosphorylation and nuclear p65 expression and downregulated I $\mathrm{B} \alpha$ expression) and associated functional proteins (RAGE, FAK, 


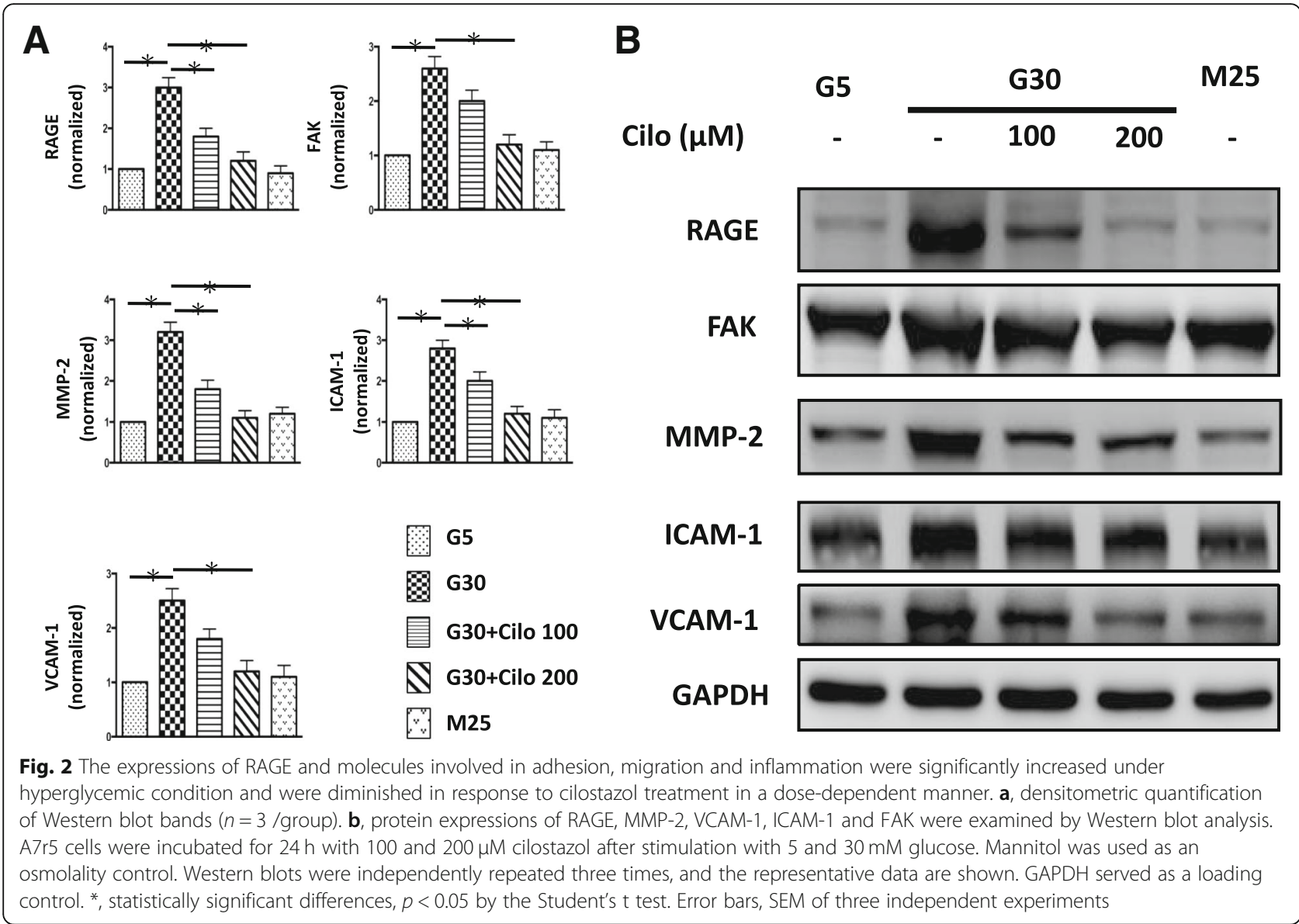

MMP-2, ICAM-1 and VCAM-1 expressions) in HG cultured A7r5 cells compared with NAC-treated A7r5 cells in HG culture (Fig. 6a, b). Compared with cilostazol or NAC alone in HG culture conditions, we found additive effects in the downstream signaling and associated proteins of cilostazol and NAC co-treated A7r5 cells (Fig. $6 \mathrm{a}, \mathrm{b})$. These results confirmed that ROS were involved in HG-induced RAGE signaling and VSMC dysfunction, and that these effects were subsequently reversed by cilostazol treatment.

\section{RAGE-ERK-NF-KB pathways were involved in the HG and} cilostazol effect on A7r5 cells

In order to confirm that the effects of $\mathrm{HG}$ and cilostazol on the A7r5 cells were through RAGE-ERK-NF-kB signaling, we added an ERK inhibitor (U0126) and nuclear p65 inhibitor (PDTA) and then cultured the cells in 30 $\mathrm{mM}$ glucose. The results showed significant changes in the downstream signaling pathways (ERK phosphorylation and nuclear p65 expression and downregulated I $\mathrm{B} \alpha$ expression) and associated functional proteins (FAK, MMP-2, ICAM-1 and VCAM-1 expressions) in the HG cultured A7r5 cells compared with the U0126treated A7r5 cells in HG culture (Fig. 7a). Further, compared with cilostazol or U0126 alone in HG culture conditions, we found additive effects in the downstream signaling and associated proteins of cilostazol and U0126 co-treated A7r5 cells (Fig. 7a). Similarly, there were significant changes in the downstream signaling and associated functional proteins after PDTA treatment in the HG cultured A7r5 cells (Fig. 7b).

\section{Discussion}

It has long been appreciated that diabetes contributes to the risk of developing coronary artery disease and multiple studies have demonstrated that hyperglycemia is strongly associated with coronary artery disease pathogenesis [15]. Hyperglycemia not only disrupts protein kinase $\mathrm{C}$ signaling and increases oxidative stress, but also enhances formation of AGEs and deteriorates vascular endothelial cell function that result in vascular inflammation, vasoconstriction, thrombosis and atherogenesis [16]. Based on current literatures, both inflammation and oxidative stress are regarded as the main etiology to lead to pathogenesis and progression of atherosclerosis in diabetes [17]. Increasing evidence has shown that the mechanisms of RAGE and its ligand families contribute to the pathogenesis of 

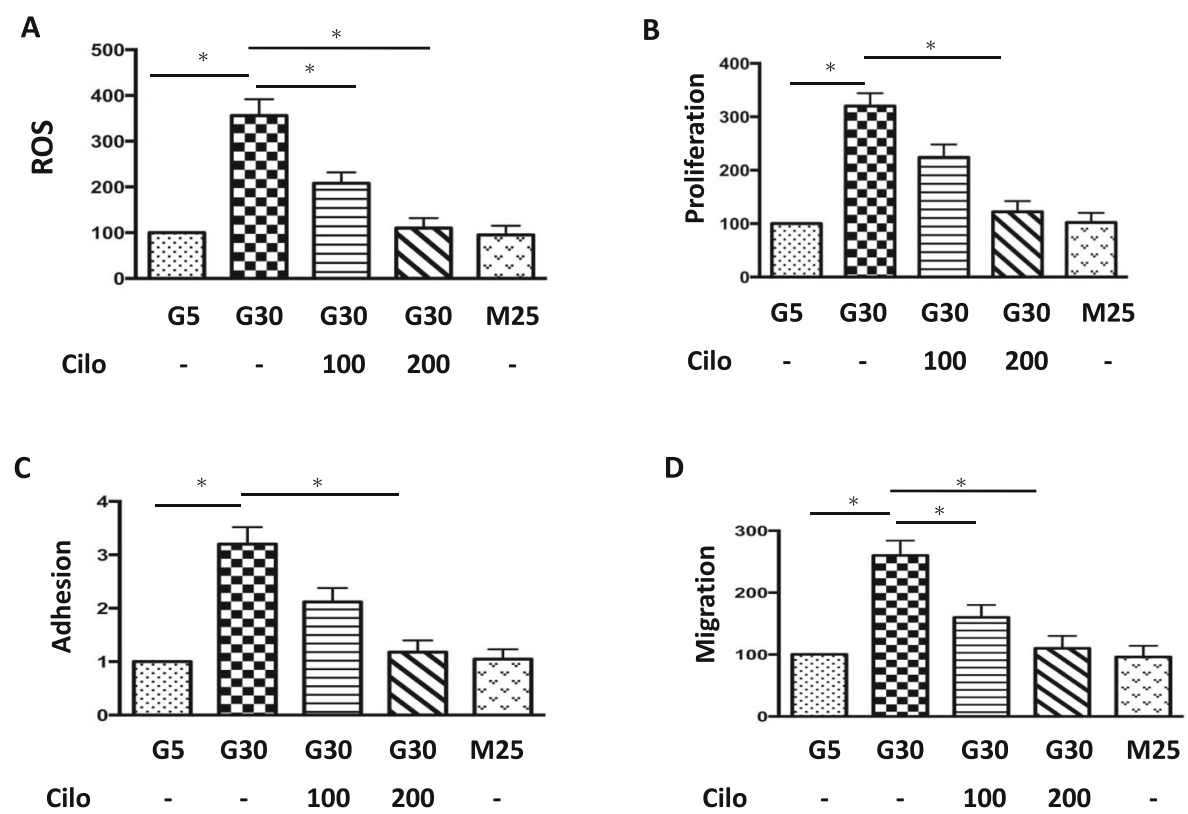

Fig. 3 Effects of HG concentration and cilostazol on A7r5 cell ROS expression, proliferation, adhesion, and migration. $\mathbf{a}$, b, $\mathbf{c}$, $\mathbf{d}$ Representative of HG concentration and cilostazol on A7r5 cell ROS expression, proliferation, adhesion, and migration. The expressions and functions were increased by HG and decreased after cilostazol treatment. Mannitol was used as an osmolality control. *, statistically significant differences, p< 0.05 by the Student's $t$ test. Error bars, SEM of three independent experiments

diabetes and to its complications in vivo and in vitro. In vitro, RAGE ligands have been shown to stimulate the migration and proliferation of VSMCs isolated from mice aorta [18]. In vivo, RAGE ligands were shown to be increased in a diabetic atherosclerotic apoE $\mathrm{E}^{-/-}$mouse model compared to nondiabetic apoE $E^{-/-}$controls [19]. In addition, diabetic $\mathrm{RAGE}^{-/-} / \mathrm{apoE}^{-/-}$double knockout mice have been shown to display decreased leukocyte recruitment, decreased proinflammatory markers, and decreased markers of oxidative stress [20]. Furthermore, significant and strong associations between cardiovascular dysfunction, vascular endothelial damage and enhanced expression of AGE-RAGE axis were observed in the clinical research [21]. Therefore, the possible therapeutic agent with its related molecular mechanism in which RAGE and its downstream signaling are involved specific to development of diabetic vasculopathy is warranted. In current research, our data from in vitro and in vivo studies provided a new mechanism of cilostazol in diabetes-related atherosclerosis. In our in vitro study, significantly decreased RAGE expression in A7r5 cells with cilostazol treatment in a dose-dependent manner was apparently observed. Furthermore, it was firmly confirmed by loss of RAGE expression test that cilostazol improved VSMC functions under HG conditions through RAGE-dependent pathways. Similarly, significant downregulation of RAGE expression was demonstrated in aortic VSMCs in the experimental murine diabetes model after cilostazol treatment.
Cilostazol, a selective PDE-III inhibitor, acts as a vasodilator and antithrombotic antiplatelet agent, and it has been shown to promote lower triglyceride levels and increase HDL in patients with PAOD [22], to improve postprandial lipemia in patients with diabetes [13], to increase nitric oxide (NO) expression with a positive effect on apoptosis [23], to prevent thrombosis after stenting [24], and to have the ability to ameliorate atherosclerotic progression [25]. Cilostazol has also been reported to cause the accumulation of cAMP in VSMCs, resulting in the upregulation of antioncogenes p53 and p21 and hepatocyte growth factor [26]. Increased suppression of the p53 protein in the cellular cycle induces apoptosis in VSMCs, causing an antiproliferative effect. Our previous findings showed that cilostazol inhibited the uremic toxin, P-cresol, induced VSMC proliferation, anti-apoptosis and migration by inhibiting the phosphorylation of PLCy, Akt and ERK [27]. Furthermore, cilostazol was demonstrated to reduce the levels of soluble adhesion molecules (ICAM-1 and VCAM-1) and expression of inflammatory factors, such as IL- $1 \beta$, IL- 6 and TNF- $\alpha$ in plasma of patients, suggestive of anti-inflammatory and angio-protective roles [28].

However, diabetes related vasculopathy is considered to be complicated rather than vascular disease alone because diabetes has various metabolic effects on macroand microcirculation in numerous vascular beds [29]. Diabetes is associated with the formation of the ROS by 
A
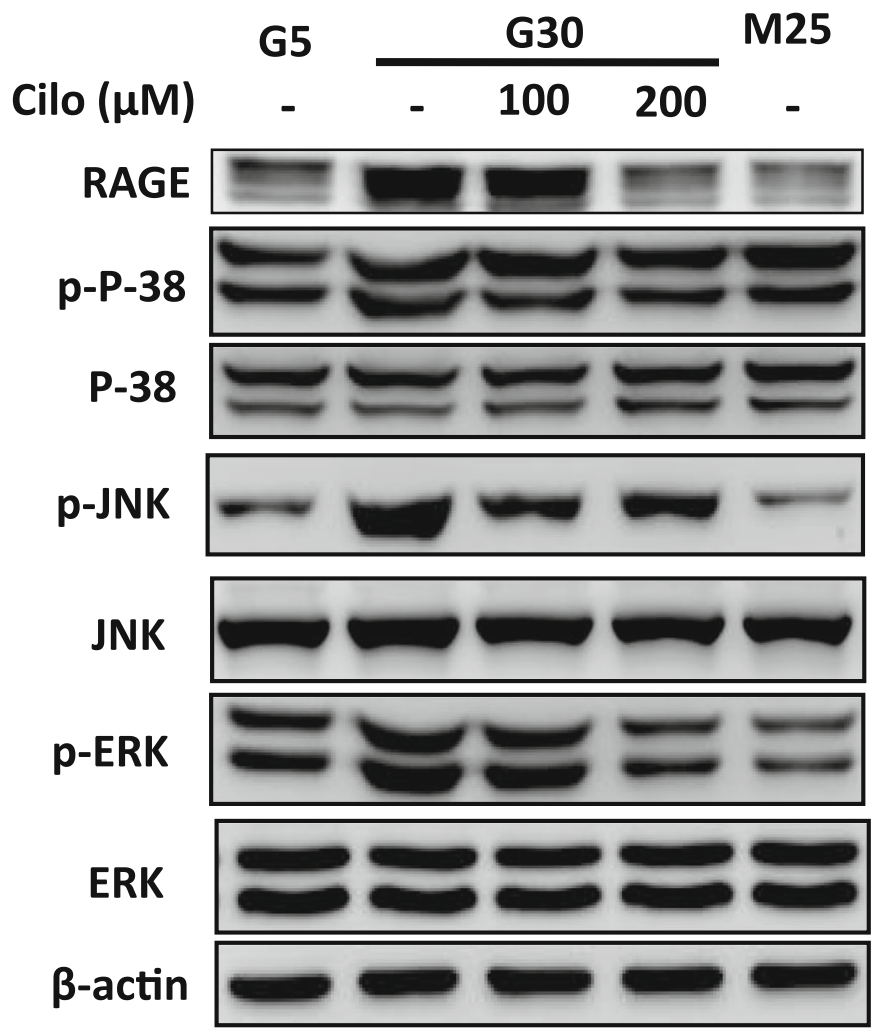
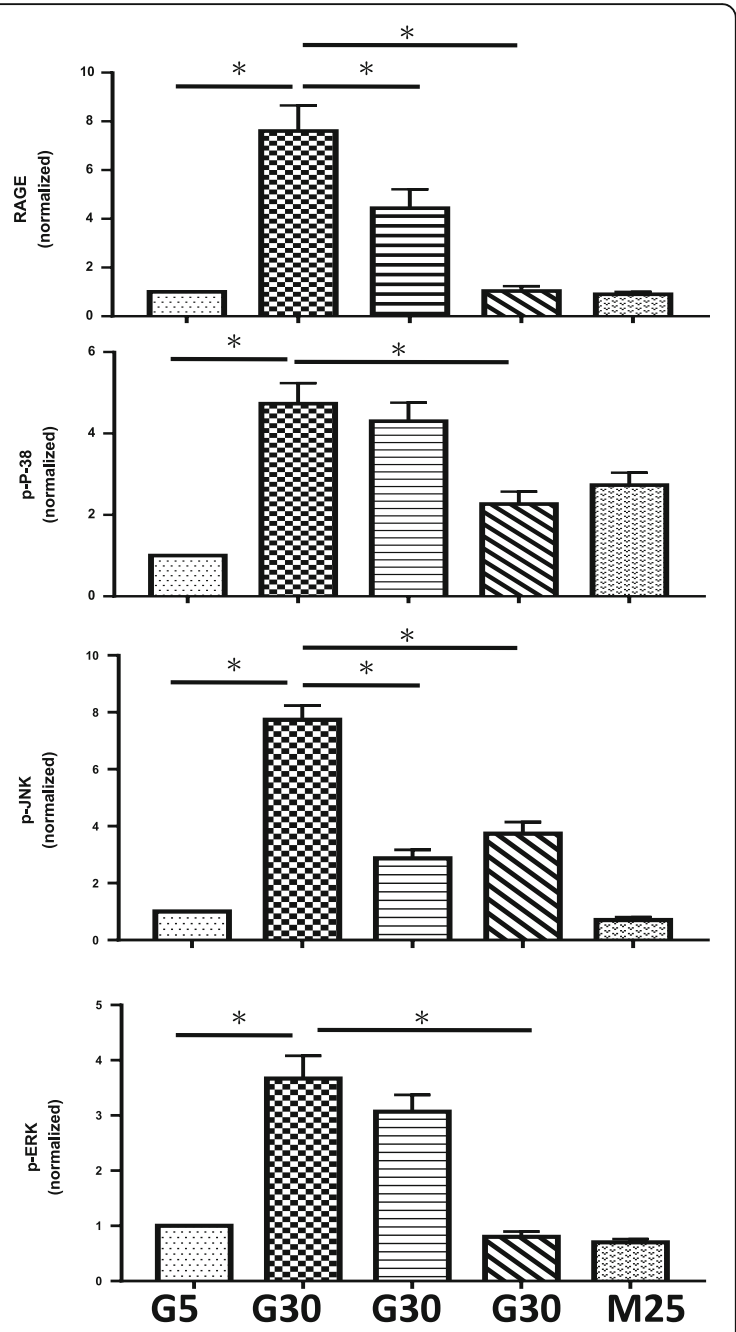

Cilo - $\quad 100200 \quad-$

B

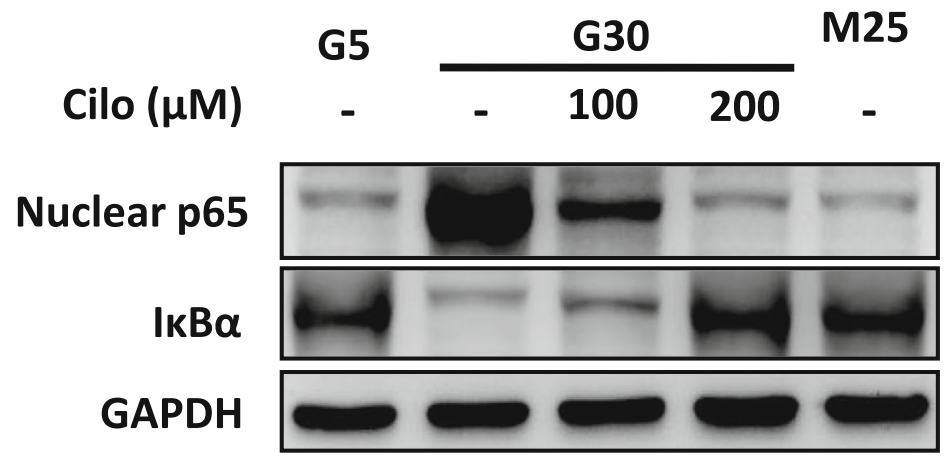

Fig. 4 Effects of HG concentration and cilostazol on A7r5 cell downstream signaling pathways. a Representative immunoblots of RAGE, p-P38, p-JNK and p-ERK expressions under treatment with HG concentration and cilostazol on A7r5 cells. The expressions were increased by HG and decreased after cilostazol treatment. b Representative immunoblots of nuclear p65 and IkBa expressions under treatment with HG concentration and cilostazol on A7r5 cells. Mannitol was used as an osmolality control. Western blots were independently repeated three times, and the representative data are shown. GAPDH served as a loading control. *, statistically significant differences, $p<0.05$ by the Student's $t$ test. Error bars, SEM of three independent experiments 

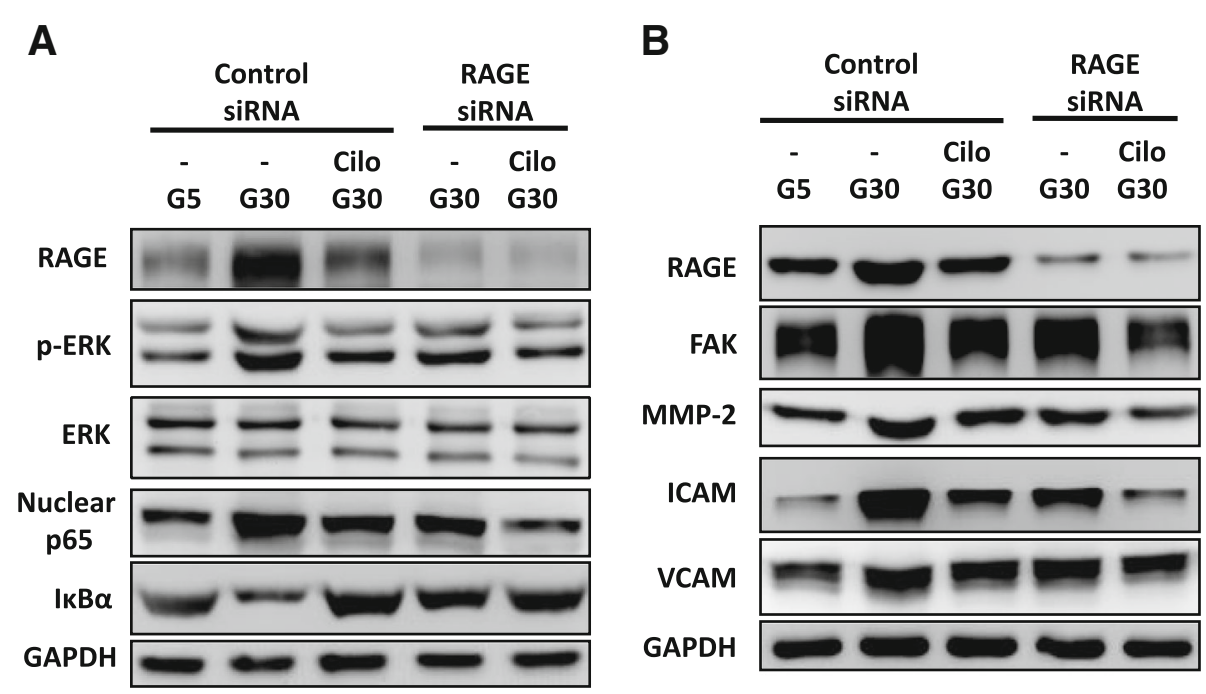

Fig. 5 Effects of cilostazol and RAGE knockdown on HG concentration-induced signaling pathways and FAK, MMP-2, ICAM-1 and VCAM-1 expressions in A7r5 cells. a Representative immunoblots of RAGE, p-ERK, nuclear p65 and IkBa expressions under treatment with $\mathrm{HG}$, cilostazol and RAGE knockdown. b Representative immunoblots of RAGE, FAK, MMP-2, ICAM-1 and VCAM-1 expressions under treatment with HG, cilostazol and RAGE knockdown. Western blots were independently repeated three times, and the representative data are shown. GAPDH served as a loading control

different pathogenic pathways and long-term complications of diabetes mellitus are associated with various oxidative reactions as well as increased free radical generation [30]. Free radicals are involved throughout the atherogenic process beginning from endothelial dysfunction, which is relevant to decline NO levels. Moreover, ROS increase the expressions of various adhesion molecules such as ICAM-1 and VCAM-1, leading to inflammatory cell recruitment. Finally, ROS increase the expressions of various growth factors and activate various stress signaling such as JNK and Pim-1, leading to the proliferation of VSMCs. Hyperglycemia also induces ROS through activation of the glycation reaction and electron transport chain in mitochondria. In addition, AGEs, insulin, and angiotensin II can also induce ROS through activation of NADPH oxidase. ROS are involved in the
A

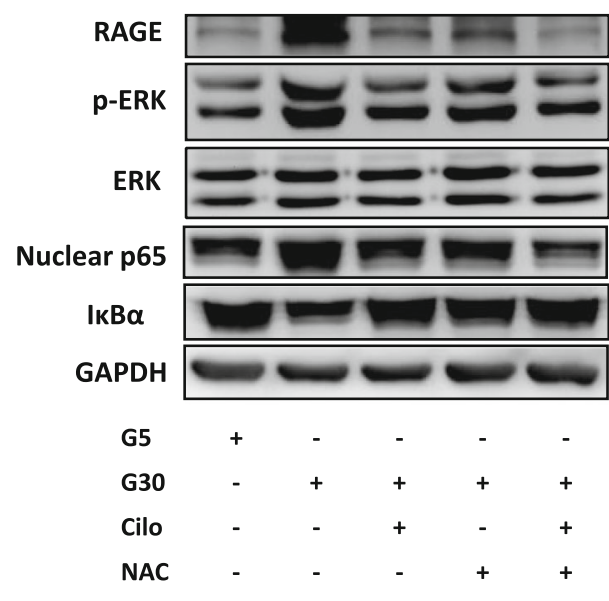

B

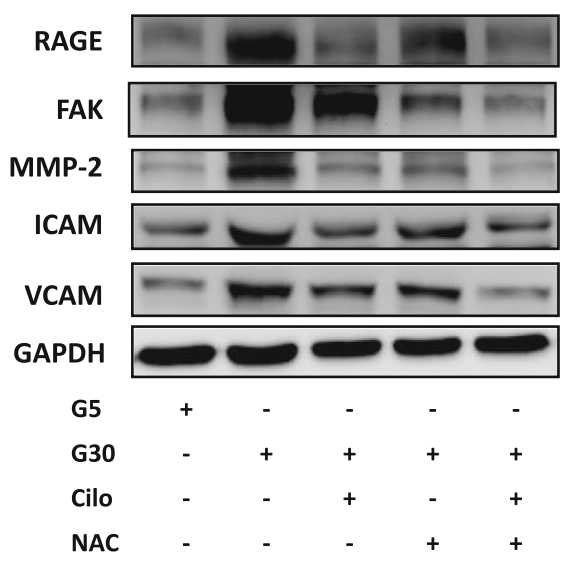

NAC: ROS inhibitor

Fig. 6 ROS expression was involved in the HG and cilostazol effects on A7r5 cells. a Representative immunoblots of RAGE, p-ERK, nuclear p65 and IKBa expressions under treatment with HG, cilostazol and an ROS inhibitor (NAC). b Representative immunoblots of RAGE, FAK, MMP-2, ICAM-1 and VCAM-1 expressions under treatment with HG, cilostazol and NAC. Treatment with HG $30 \mathrm{mM}$ and cilostazol $200 \mu \mathrm{M}$ combined with NAC in A7r5 cells. Western blots were independently repeated three times, and the representative data are shown. GAPDH served as a loading control 


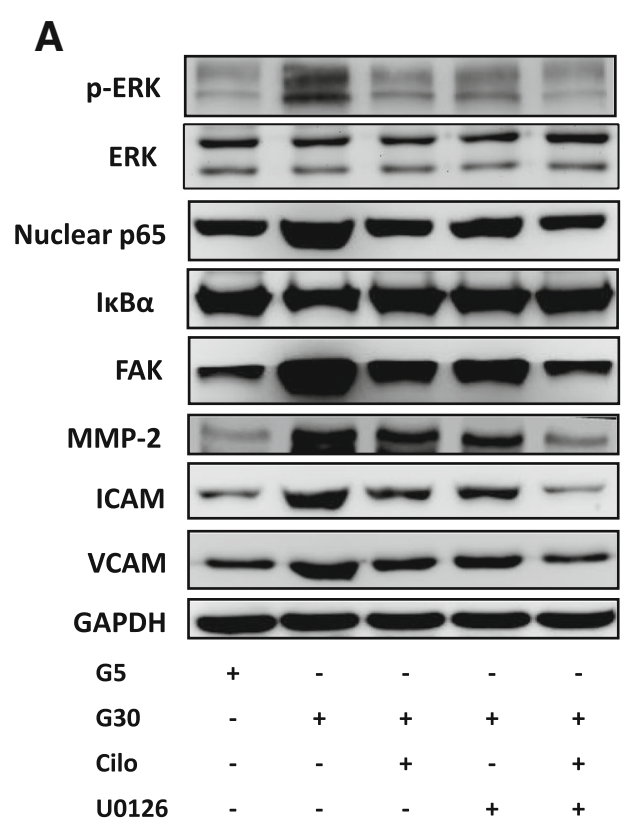

B

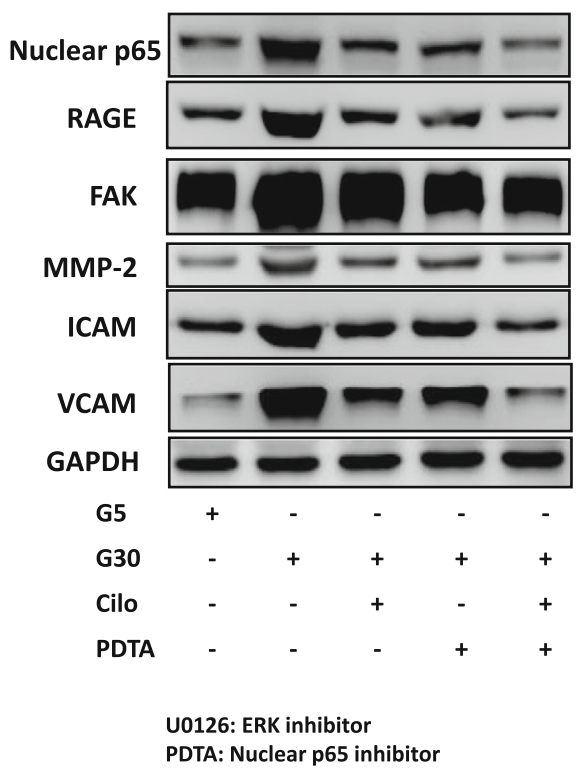

Fig. 7 RAGE-ERK-NF-KB was involved in the HG and cilostazol effects on A7r5 cells. a Representative immunoblots of RAGE, p-ERK, nuclear p65, IKBa, FAK, MMP-2, ICAM-1 and VCAM-1 expressions under treatment with HG, cilostazol and an ERK inhibitor (U0126). b Representative immunoblots of nuclear p65, RAGE, FAK, MMP-2, ICAM-1 and VCAM-1 expressions under treatment with HG, cilostazol and a nuclear p65 inhibitor (PDTA). Treatment with HG $30 \mathrm{mM}$ and cilostazol $200 \mu \mathrm{M}$ combined with U0126 and PDTA in A7r5 cells. Western blots were independently repeated three times, and the representative data are shown. GAPDH served as a loading control

progression of atherosclerosis which is often observed as a macroangiopathy under diabetic conditions [31]. Platelet and vascular stimulation result in the release of ROS that are known to influence vascular reactivity and thrombosis. Cilostazol may suppress the formation of ROS in platelets and endothelial cells and improve cellular redox status. It may also have a quenching effect on the production of hydroxyl radicals, as well as on oxidative DNA breakage by hydroxyl radicals. Recent studies have suggested that the pleiotropic effects of cilostazol are through an anti-oxidant effect and antiapoptotic effects in patients and animal models of type 2 diabetes [32]. These effects are mainly through the regulation of inflammatory cytokines such VCAM-1 [33] and ICAM-1 [34]. In a previous study, cilostazol was shown to cause a decrease in the expression of ICAM-1 via NO production in human umbilical vein endothelial cells under hyperglycemic conditions [35]. In an STZ-induced DM nephropathy rat model, cilostazol decreased the activity of ROS and could improve the levels of serum cholesterol, triglycerides, and LDL-cholesterol [36]. In the current study, our data showed that cilostazol inhibited HGinduced ROS production in a dose-dependent manner in VSMCs. Furthermore, we used an ROS inhibitor to clarify that cilostazol may improve VSMC functions under HG conditions through inhibiting ROS activity and RAGE/ERK/NF- $k B$ signaling pathways. Besides, we found increased RAGE protein expressions in the aortic VSMCs of STZ-induced diabetic rats, and that the RAGE expression in aortic tissues was significantly decreased after cilostazol treatment. Furthermore, in vitro, our results first revealed that cilostazol decreased the expressions of RAGE, FAK, MMP-2, VCAM-1 and ICAM-1 in HG cultured A7r5 cells, and also improved the proliferation, adhesion and migration of A7r5 cells. Thus, our present study strongly supported that cilostazol may have anti-oxidative and anti-inflammatory effects, thereby delaying the development of diabetic angiopathy, which was similar to conclusions of the study conducted by Yeh et al. [37].

Atherosclerosis is regarded to be a chronic inflammatory disease. In all types of atherosclerosis including that related to diabetes, the accumulation and proliferation of VSMCs in the intima is a key event. VSMC proliferation and migration induced by various growth factors can occur in a variety of pathological processes, including atherosclerosis, hypertension, diabetes, and restenosis after balloon angioplasty [38]. Cilostazol is well known to increase intracellular cAMP levels and to decrease intracellular $\mathrm{Ca}^{2+}$ levels, inhibiting platelet aggregation and inducing vasodilatation [39]. A previous study showed that cilostazol could restore HGinduced impairment of endothelial function in endothelial 
progenitor cells (EPCs) and human umbilical vein endothelial cells (HUVECs) and improve vascular angiogenesis in vitro and in vivo by modulating AMPK/ACC and probably subsequent Akt/eNOS, in parallel with or downstream of the cAMP/PKA-dependent signaling pathway. The authors suggested that cilostazol may provide therapeutic benefits in the treatment of diabetic patients with ischemic disease [40]. Recently, several lines of evidence have suggested that cilostazol has an inhibitory effect on VSMC proliferation. In addition, Aoki et al. demonstrated that cilostazol might attenuate cytokine-induced expressions of the iNOS gene by inhibiting NF- $\mathrm{KB}$ following AMPK activation in VSMCs [41]. Kim et al. also reported that cilostazol suppressed VSMC proliferation through the inactivation and downregulation of the transcription factor E2F or AMPK activation induced by HG or platelet-derived growth factor (PDGF)$\mathrm{BB}$, respectively [12, 42]. Yoo et al. also reported that cilostazol inhibited FBS-stimulated VSMC proliferation through the inhibition of ERK [43]. The authors clearly demonstrated that cilostazol significantly inhibited IL-1-induced ADAM17 expression and ERK phosphorylation in VSMCs, indicating the inhibitory effect of cilostazol on VSMC proliferation. Taken together, the therapeutic effects of cilostazol on HG induced VSMC dysfunction were demonstrated to be mainly through both inhibiting RAGE/ERK/NF- $k B$ pathways and mitigating HG-induced ROS production in our research (Fig. 8), which first indicated that the cilostazol-induced reversal of the HG-induced inhibition of VSMC functions could be mediated through RAGE/ERK/ NF- $\mathrm{kB}$ signaling pathways, rather than only through antioxidative pathways. It has been well known that cilostazol may possess beneficial effects on diabetic nephropathy by means of regulating protein kinase $\mathrm{C}$, TNF- $\alpha$, TGF$\beta$, and oxidative stress relevant NF- $\mathrm{B} B$ activation [36, 44]. Furthermore, cilostazol also appeared to limit cerebral ischemic-reperfusion injury with AGEs by inhibiting transforming growth factor- $\beta 1$ signaling [45]. Nevertheless, to our knowledge, it was first confirmed in our study that both cilostazol per se and its beneficial effects on downregulation of RAGE expression decreased the HG phosphorylation of ERK in VSMCs. It was also obviously demonstrated that an ERK inhibitor (U0126) significantly eliminated the expressions of HG-induced NF- $\mathrm{KB}$ and VSMC functional markers. In addition, cilostazol with U0126 had additive effects on HG-induced VSMC dysfunction, suggesting that ERK is a critical molecule involved in HG-induced VSMC dysfunction. ERK has been

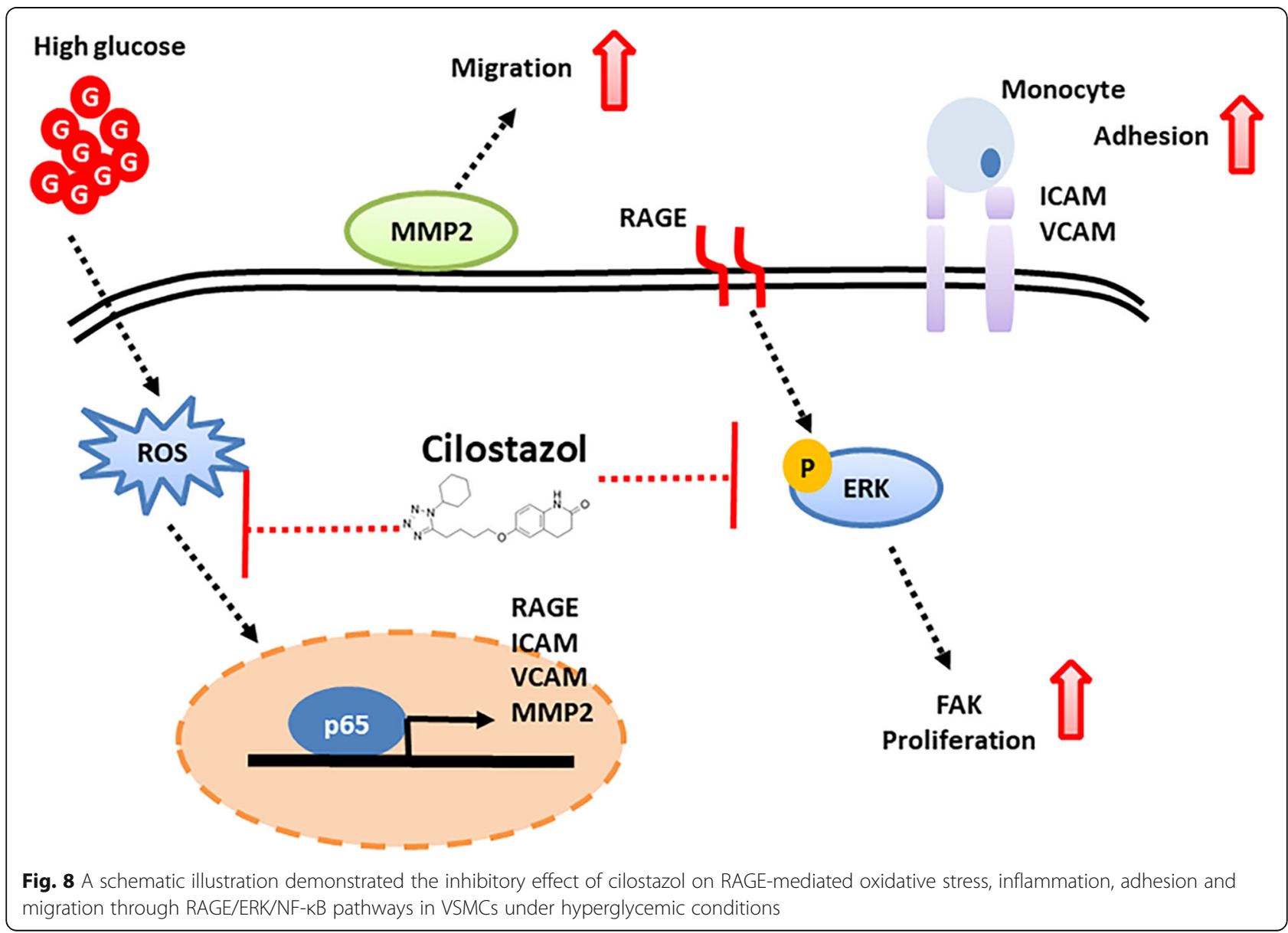


reported to be an important molecule for NF-kB activation in VSMCs [46]. We also showed that the NFkB p65 inhibitor, PDTA, could significantly inhibit HG-induced RAGE, FAK, MMP2, ICAM-1, and VCAM-1 expressions. In addition, additive effects on HG-induced VSMC dysfunction were observed with cilostazol and PDTA treatment. These data demonstrated that cilostazol reversed HG-induced VSMC dysfunction including cell proliferation through activation of RAGE/ERK/NF-kB pathways, which was quite different from that of other research groups $36,44,45]$.

\section{Conclusions}

Given that it remains unclear how cilostazol mitigates diabetes-associated vasculopathy through RAGE and its downstream signaling, the results of this study offer new insight into the signal transduction pathways that regulate cilostazol-mediated protection against HG-induced VSMC injury, and emphasize the involvement of RAGE signaling and downstream RAGE/ERK/NF- $\mathrm{kB}$ pathways. The present study also reinforces our clinical published result suggesting that cilostazol may effectively attenuate the severity of PAOD in patients with type 2 diabetes, and that plasma sRAGE is an independent determinant for improving the index of peripheral arterial insufficiency. Identifying signaling intermediaries and transcriptional mediators involved in HG-induced VSMC dysfunction provides an important insight into the pathogenesis of atherosclerosis in patients with diabetes.

\footnotetext{
Abbreviations

ABI: Ankle-brachial index; AGE: Advanced glycation end-product; CAMP: 3'-5' Cyclic adenosine monophosphate; EPCs: Endothelial progenitor cells; HDL: High-density lipoprotein; HF: High-fat; HG: High glucose; HUVECs: Human umbilical vein endothelial cells; LDL: Low-density lipoprotein; MCP-1: Monocyte chemotactic protein-1; NAC: N-acetylcysteine; NO: Nitric oxide; PAOD: Peripheral arterial occlusive disease;

PDE3: Phosphodiesterase type 3; PDGF: Platelet-derived growth factor: RAGE: Receptor for advanced glycation end-products; SRAGE: Soluble form of RAGE; STZ: Streptozotocin; VSMC: Vascular smooth muscle cell
}

\section{Acknowledgements}

This work was supported by research grants from the Ministry of Science and Technology, and Tri-Service General Hospital in Taiwan.

\section{Authors' contributions}

Conceived and designed the experiments: SCS, YJH, CHL. Performed the experiments: SCS, CYC, CFC, CHL. Analyzed the data: SCS, YJH, YSS, CYC, CFC, $\mathrm{CLH}, \mathrm{CHH}, \mathrm{YJH} C \mathrm{CHL}$, Contributed reagents/materials/analysis tools: JSL, CHL, $\mathrm{CHH}, \mathrm{CML}$, YSS. Wrote the manuscript: SCS, YJH, CHL. Overall responsibility: $\mathrm{CHL}$. All authors read and approved the final manuscript.

\section{Funding}

This work was supported by research grants from the Ministry of Science and Technology (NSC101-2314-B-016-032, NSC102-2314-B-016-007-MY2, MOST 104-2314-B-016-053, MOST 104-2314-B-016-026, MOST 105-2314-B016 -040 -MY3, MOST 105-2314-B-016 -030 -MY2, MOST 107-2314-B-016007) and Tri-Service General Hospital (TSGH-C104-121, TSGH-C104-199, TSGH-C105-005-S03, TSGH-C105-005-S04, TSGH-C105-120, TSGHC105-185, TSGH-C106-006-S01, TSGH-C106-006-S02, TSGH-C106-007-S01, TSGH-C106161, TSGH-C107-005-007-S05, TSGH-C107-007-007-S01, TSGH-C107-006-006-
S02, TSGH-C107-103, MAB-104-82, MAB-105-084, MAB-106-008, MAB-106-113, MAB-107-063) in Taiwan

\section{Availability of data and materials}

The obtained results of the research are available on reasonable request.

\section{Ethics approval and consent to participate}

The Animal Ethics Board of the National Defense Medical Center (Taipei,

Taiwan) approved all animal experimental procedures.

\section{Consent for publication}

None.

\section{Competing interests}

The authors declare that they have no competing interests.

\section{Author details}

'Division of Endocrinology and Metabolism, Department of Internal Medicine, Tri-Service General Hospital, National Defense Medical Center, Taipei, Taiwan. ${ }^{2}$ School of Dentistry, National Defense Medical Center, Taipei, Taiwan. ${ }^{3}$ Department of Oral Diagnosis and Pathology, Tri-Service General Hospital, National Defense Medical Center, Taipei, Taiwan. ${ }^{4}$ Graduate Institute of Medical Sciences, National Defense Medical Center, Taipei, Taiwan. ${ }^{5}$ Department of Pediatrics, Tri-Service General Hospital, National Defense Medical Center, Taipei, Taiwan. ${ }^{6}$ Division of Biochemistry, National Defense Medical Center, Taipei, Taiwan.

Received: 8 March 2019 Accepted: 25 July 2019

Published online: 06 September 2019

\section{References}

1. Hoyt RE. Peripheral arterial disease in people with diabetes: response to consensus statement. Diabetes Care. 2004;27(8):2095.

2. Leon BM, Maddox TM. Diabetes and cardiovascular disease: epidemiology, biological mechanisms, treatment recommendations and future research. World J Diabetes. 2015;6(13):1246-58.

3. Madonna R, De Caterina R. Cellular and molecular mechanisms of vascular injury in diabetes--part I: pathways of vascular disease in diabetes. Vasc Pharmacol. 2011;54(3-6):68-74.

4. Gonzalez I, Romero J, Rodriguez BL, Perez-Castro R, Rojas A. The immunobiology of the receptor of advanced glycation end-products: trends and challenges. Immunobiology. 2013;218(5):790-7.

5. Guerin-Dubourg A, Cournot M, Planesse C, Debussche X, Meilhac O, Rondeau $\mathrm{P}$, et al. Association between fluorescent advanced glycation endproducts and vascular complications in type 2 diabetic patients. Biomed Res Int. 2017;2017:7989180

6. Nakamura K, Sakaguchi M, Matsubara H, Akagi S, Sarashina T, Ejiri K, et al. Crucial role of RAGE in inappropriate increase of smooth muscle cells from patients with pulmonary arterial hypertension. PLoS One. 2018;13(9): e0203046.

7. Kim JM, Lee EK, Kim DH, Yu BP, Chung HY. Kaempferol modulates proinflammatory NF-kappaB activation by suppressing advanced glycation endproducts-induced NADPH oxidase. Age (Dordr). 2010;32(2):197-208.

8. Younessi P, Yoonessi A. Advanced glycation end-products and their receptor-mediated roles: inflammation and oxidative stress. Iran J Med Sci. 2011;36(3):154-66

9. Bedenis R, Stewart M, Cleanthis M, Robless P, Mikhailidis DP, Stansby G. Cilostazol for intermittent claudication. Cochrane Database Syst Rev. 2014; 10:CD003748.

10. Chapman TM, Goa KL. Cilostazol: a review of its use in intermittent claudication. Am J Cardiovasc Drugs. 2003;3(2):117-38.

11. Lee JH, Oh GT, Park SY, Choi JH, Park JG, Kim CD, et al. Cilostazol reduces atherosclerosis by inhibition of superoxide and tumor necrosis factor-alpha formation in low-density lipoprotein receptor-null mice fed high cholesterol. J Pharmacol Exp Ther. 2005;313(2):502-9.

12. Kim JE, Sung JY, Woo CH, Kang YJ, Lee KY, Kim HS, et al. Cilostazol inhibits vascular smooth muscle cell proliferation and reactive oxygen species production through activation of AMP-activated protein kinase induced by Heme Oxygenase-1. Korean J Physiol Pharmacol. 2011;15(4):203-10.

13. Liu JS, Chuang TJ, Chen JH, Lee CH, Hsieh CH, Lin TK, et al. Cilostazol attenuates the severity of peripheral arterial occlusive disease in patients 
with type 2 diabetes: the role of plasma soluble receptor for advanced glycation end-products. Endocrine. 2015;49(3):703-10.

14. Nakamura T, Terajima T, Ogata T, Ueno K, Hashimoto N, Ono K, et al. Establishment and pathophysiological characterization of type 2 diabetic mouse model produced by streptozotocin and nicotinamide. Biol Pharm Bull. 2006;29(6):1167-74.

15. Fishman SL, Sonmez H, Basman C, Singh V, Poretsky L. The role of advanced glycation end-products in the development of coronary artery disease in patients with and without diabetes mellitus: a review. Mol Med. 2018;24(1):59.

16. Henning RJ. Type-2 diabetes mellitus and cardiovascular disease. Futur Cardiol. 2018;14(6):491-509.

17. Agrawal NK, Maiti R, Dash D, Pandey BL. Cilostazol reduces inflammatory burden and oxidative stress in hypertensive type 2 diabetes mellitus patients. Pharmacol Res. 2007:56(2):118-23.

18. Manigrasso MB, Pan J, Rai V, Zhang J, Reverdatto S, Quadri N, et al. Small molecule inhibition of ligand-stimulated RAGE-DIAPH1 signal transduction. Sci Rep. 2016;6:22450.

19. Soro-Paavonen A, Watson AM, Li J, Paavonen K, Koitka A, Calkin AC, et al. Receptor for advanced glycation end products (RAGE) deficiency attenuates the development of atherosclerosis in diabetes. Diabetes. 2008;57(9):2461-9.

20. Litwinoff E, Hurtado Del Pozo C, Ramasamy R, Schmidt AM. Emerging targets for therapeutic development in diabetes and its complications: the RAGE signaling pathway. Clin Pharmacol Ther. 2015;98(2):135-44.

21. Villegas-Rodríquez ME, Uribarri J, Solorio-Meza SE, Fajardo-Araujo ME, Cai W, Torres-Graciano S, et al. The AGE-RAGE Axis and its relationship to markers of cardiovascular disease in newly diagnosed diabetic patients. PLoS One. 2016;11(7):e0159175

22. Elam MB, Heckman J, Crouse JR, Hunninghake DB, Herd JA, Davidson M, et al. Effect of the novel antiplatelet agent cilostazol on plasma lipoproteins in patients with intermittent claudication. Arterioscler Thromb Vasc Biol. 1998; 18(12):1942-7.

23. Moreira HS, Lima-Leal GA, Santos-Rocha J, Gomes-Pereira L, Duarte GP, Xavier FE. Phosphodiesterase-3 inhibitor cilostazol reverses endothelial dysfunction with ageing in rat mesenteric resistance arteries. Eur J Pharmacol. 2018:822:59-68.

24. Miura T, Miyashita Y, Soga Y, Hozawa K, Doijiri T, Ikeda U, et al. Drug-eluting versus bare-metal stent implantation with or without Cilostazol in the treatment of the superficial femoral artery. Circ Cardiovasc Interv. 2018;11(8): e006564.

25. Geng DF, Deng J, Jin DM, Wu W, Wang JF. Effect of cilostazol on the progression of carotid intima-media thickness: a meta-analysis of randomized controlled trials. Atherosclerosis. 2012;220(1):177-83.

26. Hayashi S, Morishita R, Matsushita H, Nakagami H, Taniyama Y, Nakamura T, et al. Cyclic AMP inhibited proliferation of human aortic vascular smooth muscle cells, accompanied by induction of p53 and p21. Hypertension. 2000;35(1 Pt 2):237-43.

27. Lee CH, Hung YJ, Shieh YS, Chien CY, Hsu YJ, Lin CY, et al. Cilostazol inhibits uremic toxin-induced vascular smooth muscle cell dysfunction: role of Axl signaling. Am J Physiol Renal Physiol. 2017;312(3):F398-406

28. Song F, Ji B, Chen T. Cilostazol on the expression of ICAM-1, VCAM-1 and inflammatory factors in plasma in patients with thromboangiitis obliterans. Exp Ther Med. 2018;16(3):2349-54.

29. Takeshita T, Nakagawa S, Tatsumi R, So G, Hayashi K, Tanaka K, et al. Cilostazol attenuates ischemia-reperfusion-induced blood-brain barrier dysfunction enhanced by advanced glycation end-products via transforming growth factor- $\beta 1$ signaling. Mol Cell Neurosci. 2014;60:1-9.

30. Singh R, Devi $S$, Gollen R. Role of free radical in atherosclerosis, diabetes and dyslipidaemia: larger-than-life. Diabetes Metab Res Rev. 2015;31(2):113-26.

31. Kaneto H, Katakami N, Matsuhisa M, Matsuoka TA. Role of reactive oxygen species in the progression of type 2 diabetes and atherosclerosis. Mediat Inflamm. 2010:2010:453892.

32. Kim MJ, Lee JH, Park SY, Hong KW, Kim CD, Kim KY, et al. Protection from apoptotic cell death by cilostazol, phosphodiesterase type III inhibitor, via CAMP-dependent protein kinase activation. Pharmacol Res. 2006;54(4):261-7.

33. Otsuki M, Saito H, Xu X, Sumitani S, Kouhara H, Kurabayashi M, et al. Cilostazol represses vascular cell adhesion molecule-1 gene transcription via inhibiting NF-kappaB binding to its recognition sequence. Atherosclerosis. 2001;158(1):121-8.

34. Umebayashi R, Uchida HA, Kakio Y, Subramanian V, Daugherty A, Wada J. Cilostazol Attenuates Angiotensin II-Induced Abdominal Aortic Aneurysms but Not Atherosclerosis in Apolipoprotein E-Deficient Mice. Arterioscler Thromb Vasc Biol. 2018:38(4):903-12.

35. Omi H, Okayama N, Shimizu M, Fukutomi T, Nakamura A, Imaeda K, et al. Cilostazol inhibits high glucose-mediated endothelial-neutrophil adhesion by decreasing adhesion molecule expression via NO production. Microvasc Res. 2004;68(2):119-25.

36. Lee WC, Chen HC, Wang CY, Lin PY, Ou TT, Chen CC, et al. Cilostazol ameliorates nephropathy in type 1 diabetic rats involving improvement in oxidative stress and regulation of TGF-Beta and NF-kappaB. Biosci Biotechnol Biochem. 2010;74(7):1355-61.

37. Yeh PT, Huang YH, Chang SW, Wang LC, Yang CM, Yang WS, et al. Cilostazol attenuates retinal oxidative stress and inflammation in a Streptozotocininduced diabetic animal model. Curr Eye Res. 2019;44(3):294-302.

38. Hashimoto A, Miyakoda G, Hirose Y, Mori T. Activation of endothelial nitric oxide synthase by cilostazol via a CAMP/protein kinase A- and phosphatidylinositol 3-kinase/Akt-dependent mechanism. Atherosclerosis. 2006;189(2):350-7.

39. Rondina MT, Weyrich AS. Targeting phosphodiesterases in anti-platelet therapy. Handb Exp Pharmacol. 2012;210:225-38.

40. Tseng SY, Chao TH, Li YH, Liu PY, Lee CH, Cho CL, et al. Cilostazol improves high glucose-induced impaired angiogenesis in human endothelial progenitor cells and vascular endothelial cells as well as enhances vasculoangiogenesis in hyperglycemic mice mediated by the adenosine monophosphate-activated protein kinase pathway. J Vasc Surg. 2016 Apr; 63(4):1051-62.e3.

41. Aoki C, Hattori Y, Tomizawa A, Jojima T, Kasai K. Anti-inflammatory role of cilostazol in vascular smooth muscle cells in vitro and in vivo. J Atheroscler Thromb. 2010;17(5):503-9.

42. Getz GS, Reardon CA. Animal models of atherosclerosis. Arterioscler Thromb Vasc Biol. 2012;32(5):1104-15.

43. Yoo AR, Koh SH, Cho GW, Kim SH. Inhibitory effects of cilostazol on proliferation of vascular smooth muscle cells (VSMCs) through suppression of the ERK1/2 pathway. J Atheroscler Thromb. 2010;17(10):1009-18.

44. Koike N, Takamura T, Kaneko S. Induction of reactive oxygen species from isolated rat glomeruli by protein kinase $\mathrm{C}$ activation and TNF-alpha stimulation and effects of a phosphodiesterase inhibitor. Life Sci. 2007:80(18):1721-8.

45. Takeshita T, Nakagawa S, Tatsumi R, So G, Hayashi K, Tanaka K, et al. Cilostazol attenuates ischemia-reperfusion-induced blood-brain barrier dysfunction enhanced by advanced glycation endproducts via transforming growth factor- $\beta 1$ signaling. Mol Cell Neurosci. 2014;60:1-9.

46. Jiang B, Xu S, Hou X, Pimentel DR, Brecher P, Cohen RA. Temporal control of NF-kappaB activation by ERK differentially regulates interleukin-1 betainduced gene expression. J Biol Chem. 2004;279(2):1323-9.

\section{Publisher's Note}

Springer Nature remains neutral with regard to jurisdictional claims in published maps and institutional affiliations.

Ready to submit your research? Choose BMC and benefit from

- fast, convenient online submission

- thorough peer review by experienced researchers in your field

- rapid publication on acceptance

- support for research data, including large and complex data types

- gold Open Access which fosters wider collaboration and increased citations

- maximum visibility for your research: over $100 \mathrm{M}$ website views per year

At BMC, research is always in progress.

Learn more biomedcentral.com/submissions 